\title{
Fora de campo e Campo sonoro em Cinema
}

\author{
Fausto Cruchinho
}

Universidade de Coimbra, Portugal

\begin{abstract}
Usually associated with the practice of cinema, offscreen is understood as everything and what is not contained in the field of cinema, in the plane of image and sound. This conference addresses the issue, placing the field and the field out of the image creation and its relation to what the plan entails and obliterates, in the same way as theatre space, the existence of another space that is filmic. In the same way, the sound field installs itself as the offscreen, to where it is sent what is not in the field. The sound construction, far from replicating the field of the image, establishes the possibility of the film being composed, in fact, by two films. The absence of sound in silent films would have its adherents in the totalizing idea of the art of moving images. However, offscreen was a real need to occupy this field. With the advent of sound, the transformations of silent cinema into sound cinema, established the possibility of a new cinematographic art, in fact two arts: silent cinema and sound cinema. The characteristics of both are not complementary, but rather simultaneous. That means a true relationship between the need of to show everything in field and to reinforce the idea that the field doesn't exclude the offscreen. Cinema is a sound art, like music and theatre. Like them, cinema founds its nature in the replica of the human: the voice, the sound production, the silence. Like the theatre, cinema makes use of two organs for its reception and for its creation: the eye and the ear. In this way, the cinema works the look more than the see and works more listening than hear.
\end{abstract}

Keywords: Offscreen, Soundfield, Cinema, Film, Theory

"O mundo sonoro é mais vasto que o mundo visual" Jean-Marie Straub

Quando um filme começa, a adaptação ao ecrã faz do espaço um plano, uma superfície plana, chata, bidimensional. Precisamos de nos adaptar a uma nova dimensão espacial, a do ecrã, a única que verdadeiramente existe no filme. $\mathrm{O}$ que a imagem visual nos dá é uma dimensão fotográfica de algo que teve dimensão, contexto, lugar e que aconteceu num momento dado e irrepetível. A imagem sonora também existiu nesse contexto de produção, agora ausente.

O mundo do fora de campo é o mundo do campo. Referimo-nos ao que, em cinema, se chama fora de campo, abreviatura de fora de campo fílmico. A expressão sugere a existência de um fora de campo espacial, excluído do campo visual. A entrada do sonoro pelo fora de campo introduz a existência do fora de campo visual de elementos que serão sonoros ou visuais, ou seja, a existência de algo excluído pela imagem ou por ela impossível de abranger totalmente.
O campo não designa o espaço em volta, mas a imagem que o filme obtém e esgota esse espaço. Desse modo, o fora de campo fílmico corresponde ao fora de campo visual e não ao fora de campo espacial. Como vimos, o fora de campo é sonoro. O filme institui o sonoro, inexistente sem o filme, isto é, o cinema faz nascer a imagem para instalar o som. Nem um nem outro existem fora da existência do filme.

Alguns teóricos, como Jean-Pierre Oudart, têm uma concepção topográfica do cinema: entendem que o fora de campo se situa fora do campo fílmico, no campo espacial, que se tornará campo fílmico e fora de campo de novo, sempre que a ação do filme se situa em dois campos contíguos. Sugerem mesmo que o fora de campo é o campo do desejo, aquele que o campo fílmico suscita e obtém. Sendo assim, o fora de campo confunde-se com o contra-campo, o espaço fílmico que, por natureza, o cinema não pode conter. Ora, pensar o fora de campo como aquele que o campo não pode estruturalmente conter é pensar o cinema unicamente como uma expressão visual do mundo e não como uma invenção do mundo, totalizante, portanto. Cada imagem exprime essa totalidade completa, independente de qualquer outra imagem que também exprime essa totalidade completa.

Pascal Bonitzer entende que o espaço off, o espaço do contra-campo, é o espaço imaginário que, portanto, é o lugar de inscrição do desejo do espetador, outorgando ao espetador o papel do montador do filme. A suprema frustração do desejo é o império do fora de campo. Com o jogo do ver e ser visto ficaria o cinema prisioneiro de uma organização dos planos segundo a lógica que entrega ao teatro a iniciativa da ação. 0 filme faria, deste modo, o registo de entradas e saídas em campo e em contra-campo, gerando um fora de campo infinito. Este é o modelo tradicional do realismo, partindo do princípio de que o mundo continua fora dos limites do campo da imagem. Este modelo não pensa, porém, o cinema como esgotamento da totalidade da expressão que a imagem traduz. Campo, contracampo e fora de campo estão todos contidos na imagem. Cada contra-campo e fora de campo é, de novo, e sempre, o campo.

Noël Burch trabalha o dispositivo do raccord que, através do mecanismo da continuidade temporal e da contiguidade espacial, falsifica a relação entre planos, simulando uma ação contínua através da descontinuidade da filmagem. Este mecanismo assenta na supressão espacial e temporal para criar uma dilatação ou uma contração diegética. Este mecanismo é totalmente abstrato, não tendo qualquer relação empírica com a realidade, conseguindo rarefazer qualquer causalidade e concentrandose na lógica puramente argumentativa. O cinema narrativo assenta neste modelo, a narração pura, sem preocupação de veracidade. Este modelo, o mais sofisticado de todos, é também o que isola o cinema do 
espaço e do tempo reais para o colocar como máquina narrativa, máquina de subtração. Neste sentido, no limite, pode dispensar o uso de todos os mecanismos de ambivalência entre o campo e o fora de campo, uma vez que estes perdem esse estatuto a favor da atenção do espetador ao mecanismo narrador.

A sonoridade não se reduz ao uso da voz, nomeadamente, narrativa. Ela comporta toda a panóplia acústica que compõe o mundo sonoro: o ruído, a música, a voz. A separação constitutiva entre imagem e som no cinema é inevitável porque não é possível ver o som nem ouvir a imagem. Sendo assim, a sua separação, longe de ser uma fatalidade, é ela mesma a matéria cinematográfica por excelência: o filme da imagem, o filme do som e o filme da imagem e do som. A invisibilidade do som não tem permitido até hoje circunscrever as suas características, como se fez com a imagem. Do som, podemos dizer que é alto ou baixo (volume), que é agudo ou grave (escala), não podemos tê-lo parcialmente, só podemos tê-lo e obtê-lo na sua totalidade. Ao contrário da imagem, o som não se mede pela maior ou menor quantidade do visto, neste caso pela quantidade do ouvido. Como a imagem, o som é a totalidade do mundo apresentado, ainda que a sua expressão pareça privilegiar uma só parte.

O cinema é uma arte sonora, como a música e o teatro. Como eles, o cinema funda a sua natureza na réplica do humano: a voz, a produção sonora, o silêncio. Como o teatro, o cinema faz uso de dois órgãos para a sua recepção e para a sua criação: o olho e o ouvido. Desta forma, o cinema trabalha o olhar mais do que o ver e trabalha mais o escutar do que o ouvir. Isto é, ambos os órgãos são usados como produção de recepção e trabalhados como mecanismos metacorporais. Dito de outra maneira, olhamos e escutamos através da modulação introduzida pela arte. Não vemos nem ouvimos sem a aparelhagem do olhar e do escutar. Não olhamos nem escutamos como vemos e ouvimos: a atenção é centrada num meio que dispõe e nos dispõe para o olhar e o escutar como tarefas características da criação e da recepção. Esse meio é o cinema, o teatro e a música.

Assim, o cinema instala um regime do olhar e do escutar, antes que um regime do visual e do áudio. O cinema obriga o seu espetador a escutar e a olhar, sob pena de não resultar um discurso artístico. Ao fazê-lo, o cinema estabelece o que fica reservado para a imagem e o que fica reservado para o som. As funções de cada um destes elementos distribuemse pelo campo e pelo fora de campo, sem hierarquia à partida, compreendendo que o jogo entre os dois polos pode resultar na diversificação dos sentidos e na inteligência do discurso. O fora de campo não é o lugar do imaginário, do inesperado, da sutura entre o visível e o invisível; é antes o lugar de inscrição de outro campo, aquele que joga o jogo do campo/ fora de campo e vice-versa. A esse campo chamamos campo sonoro, que corresponde a outra componente do cinema, cuja utilização permite constituir o campo e o fora de campo, alternadamente. Assim, aquilo que não é figurado no campo visual pode ser figurado no campo sonoro e vice-versa. Deste modo, a ausência de figuração na imagem e a ausência de elementos sonoros no som são situações extremas de ausência. O seu uso, ou não, configura opções na relação entre o campo e o fora de campo, permitindo este diálogo e comunhão entre as duas ausências.

Ao campo sonoro é atribuído, habitualmente, o papel de complemento da imagem, o continuador ou explicitador daquilo que se passa na imagem, seja isso a voz, o ruído, o silêncio e a música. Com essa função é criado o fora de campo, o que a imagem não pode, tecnicamente, exprimir. O facto de ser assim, habitualmente, expressão do domínio da imagem no cinema, como herdeiro das formas de representação da pintura, gravura, desenho, fotografia, ilustração, etc, não obriga a que o cinema não possa e não deva ser pensado antes como continuação do teatro e da música, justamente pela existência e potência do som, o fora de campo do cinema. Podemos encarar o fora de palco no teatro e as entradas e saídas de instrumentos na música como expressões do fora de campo nessas áreas artísticas. Trata-se, como no cinema, de fazer intervir o que faz parte do discurso artístico através dos elementos que estão nele contidos desde o princípio, desde os seus fundamentos. Como no cinema, o fora de palco e o fora de cena fazem parte do que está em palco e em cena, através da sua potência e existência: o sistema de representação institui-os como parte integrante não recusável de si mesmo.

"Das cem impressões recebidas pela mente, oitenta
e sete são transmitidas através dos olhos" David W. Griffith

O cinema é, pois, um dispositivo que cria na imagem uma força centrípeta, capaz de absorver todos os elementos à sua volta, nomeadamente o fora de campo. A presença e ausência do campo sonoro atira a imagem para o fora de campo, criando uma força centrífuga. Temos, assim, o fora de campo como uma força aglutinadora do cinema, criando no campo da imagem um centro, um vórtice de forças de atração e repulsão. Seja para dentro, seja para fora, o cinema cria um campo alargado de representação que extravasa o campo restrito da imagem. O cinema apresenta-se como uma totalidade que substitui a totalidade precária da realidade empírica. O trabalho do cinema é, portanto, um trabalho de abstração da visibilidade e da audibilidade, convergindo para uma matéria abstrata que é o filme. O trabalho do filme é o da condensação de elementos presentes e ausentes numa única natureza, à qual se atribui caráter artístico.

No entanto, Rudolf Arnheim não vê o cinema sonoro como uma nova arte, com autonomia, já que o teatro junta a imagem e a palavra com sucesso, mais sucesso do que a pintura e a escultura, artes da imagem fixa. O cinema sonoro continua a lógica do cinema mudo, a da imagem em movimento. Ao contrário, Ralph Stephenson e Jean R. Debrix veem no som múltiplas qualidades que a imagem não tem: a música, a fala e os ruídos. Porém, entendem que o som veio tornar complexa uma arte que era simples, a arte do mudo. Para Henri Agel, o cinema sonoro é uma nova arte que junta a palavra, o ruído e a música 
à imagem. O uso da voz off corresponde ao uso do fora de campo, permitindo a existência de encadeados sonoros como os encadeados visuais. Há uma arte do cinema mudo e uma arte do cinema sonoro: duas artes distintas, portanto.

Michel Chion afirma que o som tem um ponto único e imóvel, ao contrário da imagem que tem profundidade, largura e altura. Ao contrário da concepção contrapontual do cinema sonoro de Sergei Eisenstein, Michel Chion entende que o som não deve acompanhar a imagem nem ser seu contraponto, mas sim ser autónomo em relação à imagem, ser outro filme. Para Jean Mitry, a palavra no cinema não visa acrescentar ideias à imagem, uma vez que o cinema cria as suas próprias ideias. Jacques Aumont nega a existência de um fora de campo sonoro pelo facto simples de que fora do campo sonoro não há som. A imagem é tida como fazendo parte de uma parte; o som é tido como um todo que exclui outro todo ou parte.

A palavra não tem ponto de vista nem é possível têlo. O som não tem dimensão, direção e ângulo, apenas tem volume e modulação, apenas pode ser grande ou pequeno, alto ou baixo. Assim, o controle sobre o som é o controle sobre todo o som em si. Não é possível apreender aquilo que não tem controle: não temos uma parte do som nem ele se instala num campo controlável. Ao contrário da imagem, sempre passível de traduzir uma existência física, o som corresponde sempre àquilo que ele é quando produzido e não corresponde a uma reprodução mas a uma produção. Ele é som em primeira instância, não uma duplicação de outro som ou de outra realidade sonora. A imagem, ao contrário, porque tendencialmente semelhante a algo semelhante, é sempre uma segunda instância. O som é a manifestação mais próxima da sua realidade, isto é, corresponde à sua produção primária, não duplicável, uma vez que não se pode alterar a relação do som com o ouvinte como se faz com a imagem e o seu espectador. O som apresenta-se como o analogon de si próprio.

A imagem não tem, por natureza, autonomia em relação ao seu criador e ao seu destinatário. Ela é o produto de uma intenção frustrada de comunicar, só pode existir enquanto coisa em si ligado àquilo que Ihe deu origem (a criação) e não tem qualquer relação de proximidade com o seu objeto: não duplica, não substitui, é uma coisa como outra qualquer no mundo. A imagem não diz o que quer dizer nem diz o que não quer dizer, a imagem não fala, não diz, é muda. Não provoca qualquer efeito de percepção (semelhança, dissemelhança) ou de sensação (o que vê, como vê), é o receptáculo de tudo o que lá se quiser depositar. A imagem é criação mental, é exteriorização de estruturas pré-existentes e sua arrumação em estruturas recriadas fora da mente, a que é dada oportunidade de se expressar artística ou tecnicamente, com ou sem intervenção mecânica. Como natureza não autónoma, ela tende a ser incluída numa massa mais geral de elementos de significação que se constituem como linguagem. Assim, é possível referenciar a imagem por assimilação com outras configurações de imagem (escrita, volume, cor), compreendendo um universo de manifestações do ímpeto inicial de exteriorização da imagem. Porém, nenhuma imagem substitui outra, são o produto do momento inicial de figuração do processo mental que lhes deu origem. A imagem não é reflexo nem representação de nada. Ela não repete o que existe nem retoma nada sob outra aparência. Ela é pura criação mental sem origem em nada existente, nasce de manifestação de pensamento que origina uma sua tradução: imagem ou discurso igualam-se na manifestação desse pensamento. Esse pensamento é organizado e toma as vestes da imagem, com ela esgotando o primeiro propósito do pensamento: existir. Outra imagem que retenha elementos da primeira é ainda uma imagem, a mesma imagem, não sendo possível existir mais que uma imagem, assim como não é possível existir mais que uma mente. Toda a imagem se preenche de mais ou menos elementos, não sendo possível adicionar ou subtrair outros com qualquer modificação: será sempre a mesma imagem.

\section{"Cinema sonoro, monstro temível, criação contranatura, graças à qual o écran se tornará um pobre teatro, o teatro do pobre" René Clair}

Segundo Pierre Schaeffer, o ruído é o único som adequado à imagem porque a imagem só pode mostrar as coisas e o ruído é a linguagem das coisas. Já a palavra é considerada o rumor dos personagens e não o texto que têm de dizer. A música não tem importância nem é necessária ao cinema. A questão da música no cinema é a mais problemática de todos os elementos que compõem o campo sonoro. Se retirarmos a música diegética - que tem a função igual à da voz e do ruído diegéticos - a música como elemento sonoro que se sobrepõe aos restantes elementos sonoros e à imagem não tem razão de ser no cinema. Herdado das artes circenses e teatrais, a música mantém-se e está ligada ao cinema como desvio da atenção do espetador da diégese ou construção de ambiente consoante os géneros cinematográficos. A música é, portanto, um elemento espúrio do cinema, juntando mais um elemento ao espetáculo do filme.

Porém, ela não é necessária - como comprova o cinema mudo - à arte cinematográfica sonora, nem tem importância, como refere Pierre Schaeffer. Na sua teoria contra-pontual, Sergei Eisenstein e Sergei Prokofiev fazem nascer o cinema sonoro na base do uso do som da música como única manifestação do som, mantendo o cinema mudo como até então. $\mathrm{Na}$ verdade histórica, já era essa a prática da projeção de filmes mudos: filmes com música de acompanhamento. Ora, a alteração da passagem do cinema mudo para o cinema sonoro é a criação do campo sonoro que coabita com o campo visual, formando uma nova arte não dependente exclusivamente da imagem e da montagem. Na verdade, não há qualquer avanço na passagem do cinema mudo para o cinema sonoro: ainda hoje podemos fazer cinema mudo. Nem se trata de um avanço tecnológico: o cinema podia ter nascido já sonoro. Trata-se, isso sim, de duas artes cinematográficas, usando à vez a imagem ou o som ou os dois em simultâneo. A natureza mesma da arte 
cinematográfica altera-se com a introdução do campo sonoro na construção do filme: uma nova matéria que vem organizar o campo fílmico.

À semelhança da imagem, o som é obtido através do registo de algo e sua transformação em reprodução de algo. Como o som, a imagem regista algo e a sua reprodução só é possível através do movimento mecânico, através da atualização do registo. Deste modo, a coexistência em simultâneo da imagem e do som torna possível uma dinâmica de sugestão de realidade empírica, sem registo de som e de imagem e sem montagem das duas bandas. Essa simulação de reconstituição da realidade escamoteia a natureza do cinema, uma arte sonora à priori. O cinema é criação artística à partida, utilizando os modos, os seus modos, de criação. Como referimos antes, esses modos são o audível e o visível e os seus instrumentos mecânicos. O ótico e o acústico são os instrumentos da recriação, os que não pertencem ao artista. São os outros que sentem aquilo que os outros fazem.

"O cinema é a menos mimética das artes" Alain Badiou

Podemos estabelecer, após a enunciação de várias questões relativas ao cinema, que há uma elaboração teórica que tem privilegiado a relação entre referente e referido, como se o cinema fosse uma linguagem do objeto, uma obrigatória comparação entre ver e visto, entre ouvir e ouvido. A estas operações artísticas, já referidas anteriormente neste artigo, chamamos cinema sonoro, ou simplesmente cinema. No cinema, eventualmente pelas suas origens figurativas, estabeleceu-se que o cinema é cinema de alguma coisa, isto é, que a realidade se dispõe para ser filmada. À operação de filmar não se atribui, inexplicavelmente, a função de pensar. Como se a máquina não tivesse pensamento, não produzisse pensamento. O equívoco de base consiste em separar as operações artísticas próprias do filme das operações do pensamento ou de encontrar no filme as operações que levam ao pensamento não artístico, filosófico, sociológico, histórico, etc. Nestes casos, trata-se da criação de conceitos, conceptualizar a partir de um enunciado chamado filme, que é tarefa da filosofia. Porém, essa tarefa da filosofia é executada por filósofos com o objetivo de utilizar o filme como instrumento do pensamento filosófico, como se processa, qual o instrumento que pode levar o filme, os seus momentos e procedimentos, à criação de uma ideia, de um pensamento, criado para uso do filme e inútil para outro objetivo. O princípio enunciador do filme, a imagem e o som, estabelece que o mundo passa a ser apresentado como substituição, como a palavra está na vez do objeto, a música lembra o canto e o ruído vem do fragor da terra. Assim, percebemos que a origem do cinema é semelhante à origem de qualquer outra manifestação artística, vindo do princípio de substituição tão cara à arte, tão cara ao homem - o alias. Não é uma duplicação porque não tem qualquer semelhança com qualquer coisa existente; não é uma originalidade porque não parte do nada para atingir um todo. É antes uma entidade com autonomia, um em vez de algo ou de alguém, que toma a sua vontade e independência do sujeito e do objeto donde vem a sua origem.

No início deste artigo, estabelecemos uma descontinuidade entre campo e fora de campo e ainda entre campo e campo sonoro. Com esse estabelecimento queremos situar a discussão teórica do cinema fora do contexto do cinema como reprodutor da realidade e como continuação da estratégia do espetáculo. Interessou-nos antes revalorizar uma discussão teórica nascente entre historiadores e linguistas sobre a verdadeira natureza do cinema como arte sonora, como entidade devedora dum princípio enunciativo que lhe é intrinsecamente interior e que veio confirmar um desejo humano de reconfigurar o pensamento, tomando como objeto a produção de conceitos unicamente cinematográficos. A relação singular entre imagem e som tornou viável a possibilidade de existência de uma arte autónoma, em que as partes são dependentes de um todo.

\section{Bibliografia}

Agel, Henri. 1972. "A linguagem do filme: o som", in O cinema. Porto: Livraria Civilização Editora, Coleção Habitat

Arnheim, Rudolf. 1989. "Um novo laocoonte", in $A$ arte do cinema. Lisboa: Edições 70. Coleção Arte \& Comunicação

Aumont, Jacques et alli. 1983. "Le cinéma, représentation sonore", in Esthétique du film. Paris: Editions Fernand Nathan. Coleção Nathan-Université

Bonitzer, Pascal.1976. "Des hors-champs", in Le regard et la voix. Essais sur le cinéma. Paris: Union Générale d'Editions. Coleção 10/18

Bonitzer, Pascal. 1982. "Le champ aveugle", in Le champ aveugle. Essais sur le cinéma. Paris: Cahiers du Cinéma/ Gallimard

Burch, Noël. 1973. "Nana ou os dois espaços", in Praxis do cinema. Lisboa: Editorial Estampa. Coleção Praxis

Chion, Michel. 1992. Le son au cinéma. Paris: Cahiers du Cinéma

Eisenstein, Sergei. 1974. "Manifesto acerca do futuro do cinema sonoro", in Da revolução à arte, da arte à revolução. Lisboa: Editorial Presença. Coleção Biblioteca de Ciências Humanas

Journot, Marie-Thérèse. 2005. Vocabulário de cinema. Lisboa: Edições 70. Coleção Arte \& Comunicação

Martin, Marcel. 2005. "Os fenómenos sonoros", in $A$ linguagem cinematográfica. Lisboa: Dinalivro

Metz, Christian. 1980. "'Filme" no sentido absoluto", in Linguagem e cinema. São Paulo: Editora Perspectiva. Coleção Debates

Mitry, Jean. 1965. "La parole et le son", in Esthétique et psychologie du cinéma, volume 2. Paris: Editions Universitaires

Oudart, Jean-Pierre. 1969. "La suture", in Cahiers du Cinéma, $\mathrm{n}^{\circ} 211$, pp. 36-39 e n²12, pp. 50-55

Schaeffer, Pierre.1982. "L'élément non visuel au cinéma", in La Revue du Cinéma - Anthologie. Paris: Gallimard

Stephenson, Ralph e Debrix, Jean R..1969. "A quinta dimensão", in O cinema como arte. Rio de Janeiro: Zahar Editores. 